Letrônica, Porto Alegre, v. 7, n. 1, p. 366-384, jan./jun., 2014

\title{
O ESPAÇO AUTOBIOGRÁFICO MIGRANTE EM KOKIS E LAFERRIÈRE
}

\author{
MIGRANT AUTOBIOGRAPHICAL SPACE IN KOKIS AND LAFERRIÈRE
}

\author{
Luciano Passos Moraes*
}

\begin{abstract}
Resumo: Na contemporaneidade, inúmeras obras literárias focalizam a fragmentação do sujeito, a viagem, a errância, o exílio, movimentos ligados diretamente à problemática da identidade e da alteridade; nas chamadas "literaturas migrantes" nas Américas, tais aspectos são abordados com frequência. Não raro, as narrativas contemporâneas trazem traços autobiográficos, sendo seus autores exilados ou imigrantes que abordam o tema da errância a partir de seu olhar muito particular. É o caso de Sergio Kokis e de Dany Laferrière, que adotam em diversos romances seus países de origem como espaço ficcional das personagens - o Brasil e o Haiti, respectivamente. Em especial nas obras Errances (Kokis) e L'énigme du retour (Laferrière), que tratam do retorno do exilado ao país natal, a questão autobiográfica é colocada em jogo, que fragilizando as fronteiras entre ficção e verdade: os protagonistas são sujeitos migrantes (aliás, ambos escritores), cada um empreendendo o deslocamento de volta ao local de origem, retornando em momentos políticos importantes, o final de ditaduras. Tanto Kokis quanto Laferrière afirmam, em textos autobiográficos, utilizarem-se de experiências vividas como matéria para suas narrativas ficcionais, sobretudo no plano temático (os regimes totalitários que os levaram ao exílio são aludidos em alguns romances, e personagens em pleno processo de migração são frequentes). Nesse contexto, analisaremos algumas questões relativas às literaturas migrantes no Quebec e o lugar ocupado por esses dois autores, tomando como ponto de partida as obras citadas para explorar a tensão que ambos empreendem entre ficção e realidade.
\end{abstract}

Palavras-chave: Autobiografia; Autoficção; Exílio; Retorno.

Abstract: To these days, a great number of literary works have focused on the fragmentation of the contemporary subject, specially through the voyage, errance and exile, movements that denounce the problem of identity and alterity; in the context of "migrant literatures" in the Americas, these aspects are recurrent. Many contemporary narratives bring autobiographical traces of their exiled of immigrant authors, who explore the errancy through their very particular angle. It is the case of Sergio Kokis and Dany Laferrière, who adopt in several novels their homelands as fictional space of the characters - respectively, Brazil and Haiti. Especially in the novels Errances (Kokis) and L'énigme du retour (Dany Laferrière), that have to do with the return of the exiled characters, the autobiographical aspect is present, thus weakening the borders between fiction and truth: the characters are migrant writers who take their ways back to their homelands in important political moments, the end of dictatorships. Both Kokis and Laferrière affirm, in autobiographical texts, that they use personal experiences as literary material for their fictional works, especially in the thematic field (the totalitarian regimes that led them to exile are alluded in several novels, and migrant subjects are also frequent). In this context, we intend to analyze

\footnotetext{
* Doutorando em Estudos da Literatura / Literatura Comparada na Universidade Federal Fluminense (UFF). Mestre em Letras / História da Literatura pela Universidade Federal do Rio Grande (FURG). Professor do Colégio Pedro II.
} 
certain questions about the by these authors in migrant literature in Quebec and the place these authors occupy, taking the mentioned novels as a starting point to explore the tension theses authors create between fiction and reality.

Keywords: Autobiography; Autofiction; Exile; Return.

As literaturas americanas contemporâneas têm oferecido amplo campo de reflexão acerca dos temas do exílio e da migrância, seja por meio da reescrita de mitos fundadores, impulsionando a reescrita do próprio discurso historiográfico sob o viés da ficção, seja denunciando processos muito atuais de redescoberta das relações interculturais e das identidades, cada vez mais misturadas com a intensificação do deslocamento físico e psicológico do sujeito. É esperado, portanto, que tais mudanças levem em conta a migrância e a focalização do sujeito em narrativas contemporâneas: é contexto de emergência das "literaturas migrantes". A esse respeito, cabe destacar duas propostas críticas: (1) Simon Harel pensa a literatura migrante como espaço de "revelação do cruzamento das culturas" - em cuja escrita a migração ocorre em múltiplos sentidos -, e (2) Anthony Phelps considera "escrita migrante" uma expressão paradoxal, uma vez que os termos "escrita" e "migrante" apontam, respectivamente, para o fixo e para o móvel, como um tipo de jogo de "adivinhação: o que é, o que é?" (PORTO; TORRES, 2012, p. 228).

De todo modo, trata-se de ressignificar o conceito de fronteira, a partir da noção de atravessamento, transbordamento, reelaboração do imaginário migrante que embaralha os pontos de referência. Como propõe Pierre Nepveu, são "as próprias categorias do próximo e do distante, do familiar e do estrangeiro, do semelhante e do diferente que se encontram confundidas" (1988, p. 199-200).

Em L'écologie du réel, no final da década de 1980, Nepveu analisa o percurso da literatura quebequense e prevê nova maneira de se pensar as implicações identitárias nessa literatura. As relações entre coletivo e individual, identidade e fundação, são estudadas nas mais diferentes literaturas, e ao analisar o contexto do Quebec ele traz importantes contribuições aplicáveis à reflexão acerca de outras comarcas cujas literaturas sublinham as relações entre identidade e território. Para Nepveu, 
à literatura concebida como um projeto fundado sobre uma memória coletiva e uma visada totalizante, se substituíram a pluralidade, a diversidade, a movência dos textos, como a água sempre mutável de um mesmo rio: o rio sem fim da Escrita, utópico e extático, que corre eternamente em direção ao Novo e ao Desconhecido, repetindo eternamente seu murmúrio e seu encantamento (1988, p. 14).

Desde muito tempo já se encontram presentes as noções de diversidade e pluralidade no pensamento acerca da literatura do Quebec. Nesse aspecto, esse sistema literário não é muito diferente de outras literaturas repensadas, à época, com vistas a incluir no horizonte de análise seu caráter mutável e compósito - pensamento frequentemente encontrado na crítica das literaturas americanas. É quando entra em jogo a ideia da existência de literaturas ditas migrantes, cuja principal característica seria a expressão da diversidade, trazida sobretudo por escritores migrantes que imprimiriam novas formas de escrita a partir do tema da migração.

Entre fixo e móvel, entre antes, agora e devir, entre aqui e lá, sempre entre... essa preposição figura com predileção na crítica atual, na tentativa de alcançar a dimensão intermediária, interseccional, trans, que permeia os sentidos criados nas literaturas em questão. Nada mais natural, uma vez que vivemos o tempo do entre, da velocidade insuperável da troca de informações e do contato intercultural, tempo de intensificação dos fluxos, de movência constante - talvez aqui mais uma imagem oximórica, o que evidencia a necessidade de se ultrapassar a fixação de um conceito tão amplo e ao mesmo tempo tão intenso e presente.

O exílio é frequentemente uma das molas propulsoras dos conflitos identitários. As implicações do trânsito empreendido por sujeitos exilados são de ordem íntima e contundente. Fundam novas formas de imaginário e, consequentemente, configuram novos espaços para a emergência das escritas migrantes. Pierre Ouellet considera que o exílio é, portanto,

a nova condição de nosso imaginário, que só se desdobra na memória que guarda de nossas deportações passadas e no sonho que faz de um lugar de abrigo eternamente por vir, que não seja mais um solo coberto de sangue, mas o espaço aberto dos olhares e das palavras para onde convergem as verdadeiras comunidades em sua mais profunda e mais íntima movência ou transumância (2013, p. 146). ${ }^{1}$

\footnotetext{
${ }^{1}$ A tradução das citações em língua estrangeira são de minha responsabilidade, salvo quando indicado em contrário nas referências.
} 
Ainda assim, há que se pensar a figura do exilado (assim como a do estrangeiro em geral) de modo a evitar a fixação de traços, como propõe Simon Harel, para quem a experiência do "tornar-se" estrangeiro ultrapassa a mera desterritorialização. Ele diz não acreditar nos discursos construídos a partir de uma visão romântica, que fazem do estrangeiro um ser apátrido cujo único destino seria o exílio: "tornar-se estrangeiro é, em resumo, aceitar a deiscência que funda a identidade" (1992, p. 11). A noção de diferença não pode, portanto, ser reduzida a mera configuração espacial, segundo a qual alteridade é sinônimo de distanciamento físico; ao contrário, é a proximidade do estrangeiro que constitui o fator desestabilizador. Julia Kristeva, em Estrangeiros para nós mesmos, ao versar sobre as possibilidades de contato com o estrangeiro, considera que o ideal seria

\begin{abstract}
Não procurar fixar, coisificar a estrangeiridade do estrangeiro. Somente tocá-la, roçá-la, sem lhe dar estrutura definitiva. Simplesmente esboçar o seu movimento perpétuo através de alguns rostos disparatados desfilando hoje sob nossos olhos, através de algumas de suas imagens antigas, mutantes, dispersas na história. Tornar também mais leve essa estranheza, voltando a ela incessantemente - mas cada vez de forma mais rápida. Fugir do seu ódio e do seu fardo, não pelo nivelamento e pelo esquecimento, mas pela retomada harmoniosa das diferenças que ela estabelece e propaga (KRISTEVA, 1994, p. 10).
\end{abstract}

Um breve panorama das literaturas migrantes produzidas nas Américas demonstra que os temas mais recorrentes dizem respeito à figura do estrangeiro, no interior da qual se encontra o exilado. Emerge daí a problematização, via ficção, das relações entre cultura, poder e política - já que em muitos casos o movimento migratório de escritores deve-se ao descontentamento ou à discordância com o contexto sociopolítico do local de origem. 0 exílio pode ser assim entendido como a "ferida secreta, que geralmente o próprio estrangeiro desconhece, [e que] arremessa-o nesse vagar constante" (KRISTEVA, 1994, p. 12).

As diferentes manifestações da migrância são frequentes no Quebec, província que traz impressos em sua história literária traços da fragmentação identitária, da multiplicidade de expressões culturais devido à acolhida a imigrantes dos mais diversos pontos do planeta. Mas antes mesmo de se perceber como um centro de convergência de escritores migrantes, ao final da década de 1960, a literatura quebequense começa a ser pensada sob o viés da diversidade e da pluralidade, num momento em que a própria ideia de identidade nacional uniforme passa a ser refutada pela crítica. Logo na abertura 
de La littérature québécoise depuis ses origines, obra publicada no final dos anos 1990, Laurent Mailhot afirma que "os últimos 20 anos", portanto, ainda na década de 1970, "foram decisivos para a literatura quebequense. Ela se reconheceu, ela própria, tornando-se contemporânea, internacional, intergeracional, poligenérica" (1997, p. 7).

Em L'Écologie du réel, Pierre Nepveu já se propunha a pensar as escritas migrantes enquanto categoria significativa do sistema literário quebequense, uma vez que no início da década de 1980 observou-se um crescimento na difusão de obras que abordaram a temática do exílio e de hibridação cultural. Ele atribui essa particularidade a dois fatos importantes:

\begin{abstract}
0 primeiro provém do fato de que o imaginário quebequense ele próprio se definiu amplamente, desde os anos sessenta, sob o signo do exílio (psíquico, fictício), da falta, do país ausente ou inconcluso e, do próprio interior dessa negatividade, constituiu-se em imaginário migrante, plural, frequentemente cosmopolita. [...] 0 segundo fato importante que caracteriza a escrita migrante dos anos oitenta é sua coincidência com todo um movimento cultural para o qual, justamente, a mestiçagem, a hibridação, o plural, o desenraizamento são modos privilegiados, assim como, no plano formal, o retorno do narrativo, das referências autobiográficas, da representação. Em outros termos, a escrita migrante pode ser em muitos casos, quase naturalmente, tipicamente pósmoderna (NEPVEU, 1988, p. 200-201).
\end{abstract}

Vê-se aqui que a discussão acerca da presença de certa migrância nas narrativas desse período adquire importância no sentido de identificar e legitimar a presença dos elementos migrantes e híbridos em uma literatura que, até então, não tratava de exílio senão no plano psíquico. Trata-se da tomada de consciência da presença iminente da migrância nas narrativas que passavam a se proliferar, criando acesso à voz do imigrante. Vale destacar também que Nepveu já identifica, nessa época, a associação do caráter autobiográfico às escritas migrantes, ainda que só o considerasse, naquele momento, no plano formal.

Ao traçar o percurso histórico da circulação e conquista de espaço das literaturas migrantes, sobretudo a partir do lançamento da revista Vice-Versa no início da década de 1980, Pierre Ouellet destaca a difusão da figura do estrangeiro ou migrante como mediador entre culturas, passando a ocupar territórios culturais e políticos. Mas ele ressalta que

é o estrangeiro imaginário, seja a figura literária ou estética do migrante e do mestiço, que terá sido o germe real, mais eficiente do que qualquer discurso de 
natureza ética, ideológica ou política, das mutações culturais profundas que o Quebec dos últimos anos terá vivido de maneira transversal, propriamente transcultural, desde a cultura popular mais compartilhada até as práticas culturais mais experimentais, cuja dimensão exógena foi manifestada com uma força irresistível, ligando assim o destino de todo grupo cultural, no sentido antropológico do termo, à voz e à tensão singulares do estrangeiro que o habitam profundamente, à expressão sempre particular, fora do comum, ou seja, à estraneidade mais heterogênea que está no princípio de sua gênese ou de suas transformações (2008, p. 33).

A escrita migrante passa a ser considerada na literatura quebequense incluindo a discussão acerca do problema do pertencimento. Ao se ampliar os horizontes da crítica com vistas a pensar o impacto de obras de autores neoquebequenses e/ou reconhecer a importância da figura do imigrante na produção literária a partir do final dos anos 1980, passa-se a ressignificar um sistema literário em que o nacionalismo era fenômeno frequente nos estudos, sob a égide do chamado "fait québécois", considerado ameaçado por alguns críticos naquela época, segundo Ertler:

\begin{abstract}
Essa linha de divisão dos discursos que tinha certamente tornado visível a clivagem "nacional versus migrante" segue textos contemporâneos, em diferentes níveis. Visto que um dos grandes temas é o da "nação", da identidade, da origem, da filiação - em particular no contexto quebequense -, a carga emotiva que contém não pode ser facilmente neutralizada, na medida em que ele é sempre considerado em relação à questão de sua sobrevivência para a cultura específica no contexto canadense. 0 sistema literário quebequense logo reagiu à emergência dessas escritas migrantes ou neoquebequenses, cujo impacto era visível pela distribuição de prêmios literários no seio do grupo dos migrantes (2007, p. 74-5).
\end{abstract}

Hoje, as escritas migrantes ou neoquebequenses, denominação mais recente, constituem parte importante do sistema literário no Quebec. Mesmo que parte da crítica tenha retirado sua parcela "migrante" e que sua formulação conceitual não seja unanimidade, o ponto de convergência continua sendo via de regra a imigração e, consequentemente, a relação entre o contexto quebequense da produção e os diversos universos culturais presentes na bagagem dos escritores das mais diferentes origens. Híbrida por excelência, essa literatura continua a entrecruzar culturas, uma vez que "o autor migrante só compartilha uma parte do vivido com os valores e o cotidiano da sociedade canadense ou quebequense, de modo que sua identidade vê-se construída em parte de outras narrativas" em circulação, nas palavras de Ertler (2007, p. 75).

Assim, exílio, errância e outros processos correlatos têm ligação direta com a literatura produzida por escritores migrantes, trazendo outras dimensões do diálogo 
intercultural e impulsionando a problemática das identidades do sujeito contemporâneo. Certamente o Quebec constitui fértil espaço para a emergência de tais questões, em especial tendo a cidade de Montreal passado a ver vista como território da pluralidade, "cidade-mundo" (na expressão de Pierre Ouellet, 2005, p. 141) da emergência da diversidade e da riqueza do contato (ainda que conflituoso) entre as culturas. Tal constatação é conveniente ao discurso da harmonização por parte da política canadense de multiculturalismo, condizente ainda com o contexto francocanadense, que continua a difundir o discurso da diferença perante o Canadá anglófono, o que explicaria, aliás, a crescente aceitação das escritas migrantes no sistema literário do Quebec.

Sergio Kokis, afinado com essa tendência, insere-se criticamente ao pensar o estatuto do escritor migrante nas sociedades contemporâneas. Ele se refere aos escritores migrantes como "novos bárbaros", que passam a utilizar cada vez melhor a língua do colonizador, imigram e se instalam introduzindo ao local de chegada "a maneira de ser de seus mundos respectivos, suas histórias e sua sensualidade”. No plano temático, Kokis pondera que a reescrita de mitos é empreendida no lugar de mera nostalgia: "o tema constante dessas novas literaturas é o mundo estilhaçado e a ruptura dos mitos tal como os vivem de forma cotidiana esses escritores vindos de longe" (1999, p. 135).

Para Maximilien Laroche, um escritor vindo de longe é necessariamente aquele que compara, que "faz a ponte entre aqui e lá, entre outrora e hoje" (1999, p. 22). Com isso, seus personagens trazem sempre o olhar do Outro com relação à sociedade em que se estabelece, ampliando a reflexão acerca da identidade inacabada, provocando nova compreensão de seus valores e projeções:

Os personagens exóticos que ele nos apresenta nos forçam a relacioná-los aos que nos são familiares, à imagem que nós projetamos nas figuras de nossos desejos que vemos a partir de então postos em paralelo com outros desejos, outras imagens (idem).

Tal é a maior contribuição do escritor vindo de longe, para Laroche: incitar nos leitores a releitura de si mesmos a partir de um olhar de fora, crítico e provocador, que muitas vezes acaba por proporcionar um mergulho no mais profundo de si até então 
convenientemente escondido, secreto. Os valores obscurecidos por suas convenções sociais ressurgem sob esse outro olhar desestabilizador.

Dany Laferrière e Sergio Kokis destacam-se entre os escritores migrantes estabelecidos no Quebec, suas experiências pessoais de exilados constituindo matéria de criação. Tendo ambos deixado seus países em momentos históricos conturbados, as questões de escrita autobiográfica são fundamentais à leitura de suas obras.

No primeiro caso, trata-se de um escritor de origem haitiana que deixa seu país em 1976 para viver em Montreal, na província do Quebec, onde se consolida como ficcionista em 1985. A época da partida é marcada pelo regime do ditador Jean-Claude Duvalier, e as consequências da ditadura já eram conhecidas de Laferrière, uma vez que desde sua infância seu próprio pai vivia em exílio. A condição de exilado, a partida de Dany para o Canadá e as relações entre o novo mundo lá encontrado e seu país de origem oferecem matéria para diversas de suas obras.

Em entrevista por ocasião do lançamento do livro L'énigme du retour, o próprio Dany Laferrière, acerca do tema da migrância, frequente em sua obra, afirma que

Todo ser humano normal é estrangeiro até em sua família, quiçá em seu país, e não se para de aprender, de desaprender, para se adaptar, de reaprender, porque se retornou ao ponto de partida: a viagem e o retorno são os dois movimentos que os humanos fazem incessantemente em suas vidas. E aqueles que não os fazem tornam-se pessoas de caracteres um pouco limitados às vezes, eles têm medo de tudo o que é estrangeiro, de tudo o que é novo, mas mover-se pelo planeta, não aceitar as regras do jogo, não reconhecê-las, ou tentar se adaptar, é uma condição de fato humana (2009b).

Dessa forma, fica evidente a presença da estrangeiridade como aspecto propulsor da escrita de Laferrière: o caráter "entre" presente em sua literatura nada mais do que é um eco do caráter errante, móvel e transitório das identidades migrantes na contemporaineidade.

Sergio Kokis, escritor e pintor nascido no Rio de Janeiro e estabelecido em Montreal em 1969, revela-se no meio literário em 1994. O contexto de saída de Sergio Kokis não é muito diferente do de Laferrière: o Brasil acabara de viver um golpe militar que instaurou uma ditadura que duraria até 1985. 0 processo de migração serviu de matéria para a ficção de Kokis, que abordou em vários de seus romances os anos de chumbo, além de ter concebido inúmeras personagens viajantes (sob diversas nuances, 
como o exilado, o vagabundo, o marginal, a prostituta, por exemplo), seres errantes que enfrentam processos de fragilização e recomposição de suas identidades.

Na narrativa autobiográfica L'amour du lointain (2007), Kokis afirma estar em exílio não só fisicamente, mas sobretudo artisticamente: "meu exílio sempre teve para mim um sentido análogo ao de uma estadia num mundo imaginário da arte e das aventuras oníricas; só que eu o considero confortável e em consonância com minha natureza" (p. 270). Vale lembrar que escreve seus romances em língua francesa portanto, a língua do Outro, do país de acolhida - o que oferece igualmente amplo campo de investigação.

Duas obras em particular tomam por eixo central a experiência do retorno do exilado: de um lado, em Errances (1996), Kokis apresenta a trajetória da personagem Boris Nikto, intelectual exilado durante a ditadura militar que deve retornar ao Brasil após receber a notícia da anistia; de outro, em L'énigme du retour (2009), Laferrière narra uma viagem de retorno ao Haiti de um alter-ego do autor, personagem que também vive exilado no Canadá francófono e retorna a Porto Príncipe após a morte do pai.

As aproximações possíveis entre as duas obras vão além da questão do retorno. São pontos comuns entre as narrativas o recurso à figura do pai e à família como ligações importantes das personagens com suas origens. Além disso, a arte literária é aludida sob diversos enfoques: a profissão de escritor, a relação com a língua de escrita, a leitura enquanto parte integrante da constituição identitária das personagens e a construção de subtextos que remetem a obras fundadoras dos questionamentos acerca das identidades.

Ambos os heróis transitam entre personagens que disparam reflexões profundas acerca da diáspora, momentos em que questionam a validade da experiência do retorno. Em Errances, o exílio é explorado em toda sua complexidade: Boris evidencia a tensão entre usufruir da posição de sucesso que conquistara e o retorno, que fora tão esperado nos primeiros anos em exílio. As razões para o retorno e mesmo a validade desse movimento permeiam a narrativa, a partir de diálogos com outras personagens que o desafiam a se redescobrir. Em L'énigme du retour, embora a narrativa seja mais poética e concisa, tais reflexões também se fazem presentes por meio do contato com o Outro, que representa sua origem, seu passado e, portanto, sua identidade referencial. Esse Outro 
apresenta-se fragmentado e se desdobra através de diversas máscaras, seja nos membros da família ou em simples desconhecidos que são lidos e interpretados por ele de modo a revelar sua face oculta através da memória e do imaginário com relação ao lugar de origem.

0 recurso à literatura é estratégia para que a tensão entre "eu" e "o Outro" tenha lugar. A inclusão do componente metaliterário cria espaço para essas reflexões, por vezes através de subtextos que fazem eco de maneira mais ou menos evidente. No texto de Laferrière, este processo vem por meio de uma fluidez poética que conduz os relatos, sobretudo pela evocação da obra fundadora Diário de um retorno ao país natal, de Aimé Césaire. A epígrafe de L'énigme du retour já anuncia o pensamento do poeta da Martinica que se fará presente ao longo da narrativa: é o primeiro verso "No fim da madrugada..." (CÉSAIRE, 2012, p. 9) que assinala sua presença junto ao narrador, que carrega consigo o livro de Césaire e o relê constantemente, fazendo ecoar alguns de seus versos na visão que constrói na viagem ao Haiti. Texto emblemático dos escritos sobre a negritude, o poema de Césaire ressurge na narrativa poética de Laferrière com a acentuação de outros de seus pontos de reflexão, para além da questão étnica. 0 narrador aproxima a experiência sentimental abordada no texto de Césaire às sensações vividas no retorno, principalmente como forma de denunciar e tentar compreender a devastação deixada como legado pela ditadura de Duvalier.

Para exemplificar esse eco de Césaire, observemos a 39a estrofe do Diário de um retorno ao país natal:

Partir. Meu coração estalava de generosidades enfáticas. Partir... eu voltaria liso e jovem a este país meu e diria a este país cujo limo entra na composição da minha carne: "Andei por muito tempo errante e volto para a hediondez desertada das vossas chagas".

Eu voltaria a esse país meu e lhe diria: "Abraçai-me sem temor... E se não sei senão falar, é por vós que falarei."

E eu lhe diria ainda:

"Minha boca será a boca das desgraças que não têm boca, minha voz, a liberdade daquelas que se abatem no calabouço do desespero."

E ao voltar diria a mim mesmo:

"E sobretudo meu corpo assim como minha alma, livrai-vos de cruzar os braços na atitude estéril do espectador, porque a vida não é um espetáculo, um mar de dores não é um proscênio e um homem que grita não é um urso que dança..." (2012, p. 29, grifo nosso). 
Esta passagem denuncia o caráter ambíguo do retorno: de um lado, a memória evoca o sentimento negativo mantido por aquele que parte em um contexto conturbado, de outro, outra face da memória acessa, ao mesmo tempo, certa ternura em direção às origens que se intensifica após a partida, como o corpo abraçado por esse "país meu". É importante levar em consideração que, neste ponto do poema, o retorno é ainda hipotético, marcado pelo uso do modo condicional (no original), aqui traduzido com o emprego do futuro do pretérito.

Paralelamente, vejamos o seguinte trecho de L'énigme du retour:

\begin{abstract}
O ditador exige estar no centro de nossa vida e o que eu fiz de melhor na minha foi tê-lo tirado de minha existência. Confesso que para isso me foi necessário jogar às vezes a criança com a água do banho.

Eu então parti e depois voltei. As coisas não se moveram nem um pouco. Indo ver minha mãe esta noite, atravessei o mercado. As luminárias acesas me dão a impressão de caminhar em um sonho. Uma garotinha, em um vestidinho de jersey rosa, dorme nos braços da mãe que contabiliza a receita do dia. Esta ternura que permite aceitar todo o resto já me esgotou e não tardará a esgotar meu sobrinho. (2009a, p. 138).
\end{abstract}

Se o retorno de Césaire inicia-se hipotético, marcado no poema pelo uso do modo condicional, traduzido para o português com o emprego do futuro do pretérito (voltaria, veria, diria), o retorno do narrador de Laferrière, por outro lado, é narrado no pretérito perfeito ou no presente do indicativo. 0 acesso à memória é feito por vezes com certa doçura, reinventando vivências da infância, outras vezes sob o olhar melancólico do exilado em regresso. 0 emprego desses tempos verbais aproxima o tempo da leitura ao da diegese, indicando que algumas das ações já aconteceram, como se se tratasse da realização do que, em Césaire, era apenas hipótese ou profecia.

Em Errances, a literatura está igualmente presente, sendo uma primeira evidência a profissão de escritor. De maneira similar a L'énigme du retour, o ofício da escrita literária permeia as reflexões, uma vez que ambos os heróis são escritores. Na obra de Kokis, entretanto, a questão linguística é um dos componentes postos em jogo, já que o herói, tal como seu autor, escreve em língua estrangeira e traz essa problemática em várias passagens - algumas das quais são narradas ironicamente com vistas a ressignificar o lugar do escritor e as questões de autoria, sem deixar de reavaliar os valores que permeiam a história literária nos lugares por onde passa. 
Também há o recurso a outros textos que dialogam com a narrativa principal, como a alusão à obra do escritor inglês de origem ucraniana Joseph Conrad. Além disso, um elemento recorrente em diversas obras de Kokis é o debate em torno da filosofia e da crítica literária. Em Errances, particularmente, há diversas cenas narradas com ironia, em que Boris discute com seus companheiros sobre política, trabalho intelectual, literatura. Nessa empreitada, destacam-se as reflexões sobre o exílio, posição "entre" que permite ao herói fazer explodirem discussões de uma "agressividade juvenil", como em "Desde todos esses anos, ele estava habituado ao exterior indiferente que ele tinha tão penosamente construído para não se fundir nessa Europa estrangeira" (1996, p. 151). Há muitos outros momentos aparentemente banais, cotidianos, mas nos quais subjaz a migrância como tema, ou como razão para explicar este ou aquele comportamento das personagens.

Quanto ao retorno, desde o início do texto o narrador deixa explícitas as reações adversas do herói: é o momento em que todas as reflexões em torno da condição de estrangeiro tomam força. Logo nas primeiras páginas o narrador evoca o sentimento de incerteza:

\footnotetext{
Sua sombra se prolongava para a frente e para trás entre os postes, e esse movimento de pêndulo lhe trouxe lembranças que ele tinha durante muito tempo conseguido esconder sob sua carcaça de estrangeiro. [...] Desde o tempo em que ele vivia só com suas lembranças, arranjando-as a sua maneira para conferir certa coerência a sua vida, ele não estava mais certo de nada (1996, p. 15).
}

Nas obras dos dois autores aqui em questão, é incontornável pensar nas estratégias de retomada de experiências pessoais vividas como matéria de criação ficcional. Na atualidade, as questões de autonarração estão em voga, sendo fragilizados sucessivamente os limites entre ficção e realidade. Tanto Kokis quanto Laferrière escreveram textos que tangem o espaço autobiográfico, nos quais deixam transparente a influência de suas histórias de vida naquelas de suas personagens. Além disso, diversas entrevistas e artigos estão disponíveis, a partir dos quais não resta dúvida de que o componente biográfico está espalhado no conjunto de suas ficções. Em entrevista ao jornal La Presse em 2010, por exemplo, Kokis deixa pistas das relações entre ficção e biografia: "Nós somos todos romancistas de nossa vida. Nossa identidade é um produto 
de ficção, e cada um constrói sua narrativa segundo os acontecimentos" (apud LAPOINTE, 2010).

Tanto Kokis quanto Laferrière põem em xeque algumas bases das teorias acerca das escritas confessionais, sobretudo o segundo, que emprega a palavra "romance" junto aos títulos de suas obras mas traz como narrador e personagem principal um escritor com traços muito similares à história de vida do autor. Para além das condições estabelecidas por Philippe Lejeune na obra $O$ pacto autobiográfico (publicado pela primeira vez em 1975) para que uma obra seja considerada como autobiográfica, esses autores embaralham as instâncias narrador, personagem e autor a partir de novas definições de uma identidade de exilado.

Ambos evocam o sentimento existencial de todo aquele que escreve sobre si, o impulso que o conduz ao ato de repassar pelos pontos principais nos quais se constrói a identidade do sujeito. Trata-se, portanto, de mais do que simples rememoração: o processo de reelaboração passa inevitavelmente pela memória. Porém, em se tratando de literatura, a inclusão do componente ficcional abre espaço para que se pense o uso poético do vivido, fazendo coexistir o factual e o inventado, para além de estratégias de categorização.

No processo de hibridação entre ficção e autobiografia, o acesso à memória que serve de matéria para os relatos passa pela questão da fabulação, procedimento observado nas obras de Kokis e de Laferrière. A esse respeito, Héliane Kohler afirma que

\footnotetext{
Operando segundo vias comparáveis à criação literária, a memória, vale lembrar, exige constantemente um trabalho de releitura da parte do sujeitopensante, demandando a cada vez uma nova organização e uma nova interpretação do passado. Também a "fabulação" de que fala Kokis em suas considerações metatextuais (enquanto escritor que evoca e narra suas lembranças) e metapictóricas tem a ver, de um lado, com uma ficcionalização de suas lembranças e, de outro, com uma deformação voluntária ou não de outras (KOHLER, 2011, p. 62).
}

Explorar o espaço da memória é, necessariamente, adentrar aquele da ficção, da fabulação, sem deixar de fora o componente da seleção e exclusão de elementos. Para Nancy Huston, 
A nossa memória é uma ficção. Isso não significa que ela seja falsa, mas que, mesmo não sendo solicitada, ela passa o tempo todo ordenando, associando, articulando, selecionando, excluindo, esquecendo, ou seja, construindo, fabulando (HUSTON, 2010, p. 24).

Não existe o mito de um lado e a realidade de outro. 0 imaginário não apenas faz parte da realidade humana, ele a caracteriza e a engendra (Op. cit., p. 87).

Assim, entender a fabulação como parte integrante da vida humana pode ser uma pista para que se saia da dualidade realidade versus invenção. Ao explorarem o espaço autobiográfico, esses escritores hibridizam as duas instâncias, levando-as a seus limites e mostrando que há que se mudar de perspectiva: não procurar o "real", o "verdadeiro", e sim compreender e admitir que nossa realidade só toma forma a partir da fabulação, da invenção. Huston também menciona a estratégia da criação de máscaras no momento da criação literária:

Portanto, não existe fronteira estanque entre "vida verdadeira" e ficção; uma alimenta a outra e dela se alimenta.

Só conseguimos agir e compreender graças à identificação, ao deslocamento, ao afastamento, à simplificação e à essencialização, à semelhança e à representação... Enfim, graças à máscara (0p. cit., p. 123).

Segundo Jean-Louis Jeannelle, quando analisa o gênero Memórias, o autor é mandatário de um "poder testemunhal" a partir de experiências que vão além das questões individuais vividas. Trata-se dos "valores que emanam de um percurso", pois a autoridade delegada ao autor "justifica o ato de autonarração da parte do memorialista e coloca os leitores em situação de tomar conta da herança que ele lhes confia" (2012)2.

Fica clara, segundo essa perspectiva, a dupla articulação de fatores: de um lado, o individualismo é aparentemente o fator que impulsiona tais narrativas, já que o escritor empreende uma autoanálise profunda da qual resultam relatos centrados no eu (sua experiência, suas influências, seus caminhos muito pessoais, mesmo que por vezes ele se esconda sob diversas máscaras); de outro, em obras associadas à migrância, verifica-se com frequência a abordagem de experiências coletivas, sobretudo na constituição de comunidades culturais que compartilham alguns dos componentes inicialmente tidos como individuais.

Em Kokis e em Laferrière o processo de recepção do movimento migratório empreendido via literatura revela o problema da identificação, constituindo um

\footnotetext{
2 Texto de conferência apresentada na Universidade Federal Fluminense em 4 de junho de 2012, intitulada "Posturas de si e nomes de gênero".
} 
paradoxo: entrar no espaço autobiográfico significa, por um lado, mergulhar no mais profundo de si, individualizando o discurso; por outro, evoca o sentimento de identificação com uma coletividade que apresenta traços compartilhados de nãopertencimento, de engajamento, de busca pela expressão da voz sufocada das minorias étnicas ou culturais.

Se a história tradicional tende mesmo a "afastar o passado do presente", nos termos de Paul Ricoeur (1997, p. 249), não só as novas narrativas historiográficas tentam atualizar a noção de tempo: também as narrativas migrantes tentam dar conta das relações entre o passado histórico e o presente vivido no deslocamento do sujeito. A arte literária tem essa dupla capacidade, de atualizar o discurso historiográfico via ficção e de tensionar os limites entre real e ficcional. Nas palavras de Pierre Nepveu, o poder da literatura é o de

\begin{abstract}
inscrever-se não na metade exata [entre a favor e contra], mas numa certa complexidade, articulando posições adversas - e o romance em particular pode fazê-lo. Há certamente uma relação com o identitário que é a relação com uma língua, com um lugar, mas ao mesmo tempo a literatura se inscreve na tensão e na abertura, e ela não se fixa no dogmatismo. Seus equívocos fazem justiça a toda a riqueza efervescente de nossa realidade. A literatura tem essa capacidade de regenerar nossa relação com o real, sem que ela sirva necessariamente a um objetivo preciso (2010, p. 17).
\end{abstract}

Os limites da verdade, já postos em dúvida na reavaliação da história (e da literatura) a partir da emergência das pequenas narrativas, estão também em xeque quando se entra no campo das escritas de si, sobretudo no âmbito das literaturas migrantes. Ouellette-Michalska aproxima as duas fragilizações da noção de verdade, a histórica e a literária, situando a autoficção em espaço intermediário:

A autoficção, não completamente narrativa nem completamente romance, se insere em uma época de suspensão da crença histórica. É uma espécie de imagem congelada, o tempo que os bondes da História partem novamente como outrora, ou de outra maneira, se por acaso eles estão ainda em funcionamento (2007, p. 72).

O termo autoficção, proposto por Serge Doubrovsky em Fils (1977), aponta para a tentativa de "designar indistintamente os escritos factuais ou romanescos de natureza autobiográfica" (VILAIN, 2005, p. 171). Na autoficção, além da identidade nominal entre personagem, autor e narrador, é empregado o tempo presente (diferentemente da autobiografia, em que o tempo passado é privilegiado, segundo o pacto autobiográfico 
estabelecido por Lejeune), com o objetivo de aproximar o leitor da narrativa e assim implicá-lo, provocando seu acompanhamento, estendendo a ele a vida do sujeito em questão: "uma das grandes funções do presente é de tornar a coisa imediata tanto para o autor quanto para o leitor" (op. cit., p. 185).

Retomamos aqui tais ideias porque, embora tangenciem o espaço autobiográfico, Sergio Kokis e Dany Laferrière recusam seu enquadramento em qualquer categoria teórica a esse respeito. Se observarmos seus textos de caráter autobiográfico encontraremos diversos exemplos dessa postura, dos quais retomamos dois.

Logo na introdução de L'amour du lointain, Kokis declara tratar-se de relato muito pessoal, uma proposta diferente da de criar um texto ficcional (2012, p. 11). Esse primeiro contato leva a pensar na ideia de um texto autobiográfico. No entanto, essa suspeita é logo desafiada:

\begin{abstract}
Mas atenção, leitor ocioso ou crítico rancoroso: lembrem-se que isso não é uma autobiografia nem uma confissão, mas somente uma tentativa de autorretrato. Sou eu, o artista, e eu falarei unicamente do que ajudará a me compreender. Muitas coisas íntimas, coisas preciosas ou coisas que tenho ainda dificuldade de aceitar continuarão veladas porque elas só dizem respeito a mim. Não se incomodem muito com a verdade e divirtam-se antes com a verossimilhança (Op. cit., p. 38).
\end{abstract}

Posicionando-se contrário à autobiografia nesse texto, Kokis nos leva a pensar essa recusa também em sua obra literária, em que estabelece um jogo no qual ficção e experiências vividas encontram-se embaralhadas. Ele insiste em que sua leitura não seja limitada à noção de autobiografia, e é justamente no espaço entre autobiográfico e ficcional que se encontra a maior riqueza de sua obra.

Laferrière, por sua vez, também desestabiliza as relações entre factual e ficcional. Em seu livro mais recente, Journal d'un écrivain en pyjama, ele traz ao público leitor uma espécie de compilação de reflexões acerca do fazer literário. Dirigindo-se a um escritor iniciante, oferece dicas a respeito do ofício da escrita: é um pretexto para revisitar momentos importantes de sua vida literária e comentar aspectos dos bastidores da criação de sua obra:

O rebanho é o que outros chamam de obra - e o escritor é seu pastor. A gente publica livros um pouco esparsos, e chegando a uma certa idade, sentimos a necessidade de reuni-los. A gente logo se irrita quando um deles tenta se distanciar do rebanho. Devemos logo em seguida trazê-lo de volta ao grupo. A gente se pergunta o que liga cada um desses romances um ao outro. Eu, ou se quiserem, o autor. Sou eu esse longo romance que se declina em diversas 
sequências. No meu caso é um monólogo que dura quase trinta anos. Durante todos esses anos eu brinquei de colocar juntas essas vinte e seis letras do alfabeto afim de expressar o mais claramente possível minha visão das coisas. Eu devo precisar que esse eu nada tem a ver com a autoficção. É o pastor com seu cachorro (o dicionário). Minhas ovelhas estão marcadas (meus editores). Eu não sinto muito esse livro (o que vocês estão lendo). E no entanto são minhas experiências de leitor e de escritor que eu alinho aqui num espeto. Eu acordei essa manhã me dizendo que faltava a esse livro essa coisa indefinível que me permitiria reconhecê-lo em qualquer lugar. Mas o quê? Falta-me injetar nele essa dose necessária de sensibilidade pessoal. Apropriar-me desse livro. Para isso eu devo entrar nele (2013, p. 33).

Sua recusa da autoficção vem dessa impossibilidade de se categorizar teoricamente o trabalho de uma vida; cada livro é uma entidade independente que ele tenta reagrupar sob um fio condutor, e esse fio é o "eu" impresso em tantas páginas vale lembrar que ele próprio propõe chamar o conjunto de seus dez primeiros romances de "autobiografia americana". Mas daí a se associar sua literatura a uma autobiografia nos termos tradicionais há uma série de lacunas, fragmentações e complexidades que tornam sua leitura sob o viés do espaço autobiográfico ainda mais instigante.

Para além da problematização conceitual acerca do espaço autobiográfico, não restam dúvidas de que Kokis e Laferrière tangenciam esse campo de forma complexa e desafiam os limites da crítica. Nada mais natural, considerando que cada um desses escritores "vindos de longe" traz na bagagem uma multiplicidade de universos, compostos de experiências individuais ou coletivas, das quais que se servem livremente ao comporem representações da sociedade contemporânea através da rememoração e da fabulação. Sem deixar de tocar as feridas profundas deixadas pelos regimes totalitários de que se originam, destacam-se na corrente de exilados que se apropriam da literatura para imprimir sua existência através de leituras muito particulares do mundo de que fazem parte.

\section{Referências}

CÉSAIRE, Aimé. Cahier d'un retour au pays natal = Diário de um retorno ao país natal. Tradução Lilian Pestre de Almeida. São Paulo: EdUSP, 2012.

DOUBROVSKY, Serge. Entrevista a Philippe Vilain. In: VILAIN, Philippe. Défense de Narcisse. Paris: Grasset, 2005. p. 169-235.

ERTLER, Klaus-Dieter. Les écritures migrantes ou néo-québécoises dans le système littéraire contemporain du Québec: Sergio Kokis et "l'amour du lointain". In: MOREL, Pierre (Org.). Parcours québécois: introduction à la littérature du Québec. Chisinau: 
Cartier, 2007. p. 72-80.

HAREL, Simon. L'étranger en personne. In: (Org.). L'étranger dans tous ses états: enjeux culturels et littéraires. Montreal: XYZ, 1992. p. 9-26.

HUSTON, Nancy. A espécie fabuladora: um breve estudo sobre a humanidade. Tradução Ilana Heineberg. Porto Alegre: L\&PM, 2010.

KOKIS, Sergio. L'amour du lointain: récit en marge des textes (Collection Prise Deux). Montreal: Lévesque éditeur, 2012.

Solitude entre deux rives. In: Tangences n. 59. Rimouski: UQAR, 1999. p. 133-137. Disponível em: <http://www.erudit.org/revue/tce/1999/v/n59/025998ar.html>. Acesso: em 24 set. 2013.

Errances. Montreal: XYZ, 1996.

KOHLER, Héliane. Mémoire, écriture et peinture chez Sergio Kokis. L’Amour du lointain - un discours d'exploration identitaire et de réflexions épistémologiques. In: e-CRIT3224 n. 2. Besançon: Université de Franche-Comté, 2011. Disponível em: <http://ecrit3224.univ-fcomte.fr/download/3224-ecrit/document/numero_2/5_kohler_5970.pdf $>$. Acesso em: 9 out. 2013. p. 59-70.

KRISTEVA, Julia. Estrangeiros para nós mesmos. Tradução Maria Carlota Carvalho Gomes. Rio de Janeiro: Rocco, 1994.

LAFERRIÈRE, Dany. Journal d'un écrivain en pyjama. Paris: Grasset, 2013.

. L'énigme du retour. Montreal: Boréal, 2009a.

—_. Depoimento ao canal Hachette Vidéos. 2009b. Disponível em: <http://www.youtube.com/ watch?v=iu1SNYvDMQk>. Acesso em: 15 ago. 2013.

LAPOINTE, Josée. Sergio Kokis: l'année Kokis. In: LaPresse.ca. 2010. Disponível em: <http://www.lapresse.ca/arts/livres/201010/15/01-4332682-sergio-kokis-lanneekokis.php>. Acesso em: 9 out. 2013.

LAROCHE, Maximilien. Du bon usage des écrivains qui viennent de loin. In: Tangences $\mathrm{n}$. 59. Rimouski: UQAR, 1999. p. 20-25. Disponível em: <http://www.erudit.org/revue/tce /1999/v/n59/025998ar.html>. Acesso em: 24 set. 2013.

MAILHOT, Laurent. La littérature québécoise depuis ses origines. Montréal: Typo, 1997.

NEPVEU, Pierre. Dire la compléxité du réel: entretien avec Julien-Bernard Chabot. In: Chameaux n. 3. Québec, 2010, p. 15-20. Disponível em: <http://revuechameaux. wordpress.com/numeros/n\%C2\%BA-3-automne-2010/>. Acesso em: 8 ago. 2013.

L'écologie du réel: mort et naissance de la littérature québécoise contemporaine. Montreal: Boréal, 1988. 
OUELLET, Pierre. As palavras migratórias. As identidades migrantes: a paixão do outro. Tradução Luciano Passos Moraes. In: HANCIAU, Nubia; DION, Sylvie (Orgs.). A literatura na história, a história na literatura. Rio Grande: Editora da FURG, 2013. p. 145-170.

. Mobilités culturelles et mouvements de l'histoire. In: Interfaces Brasil Canadá n. 8. Rio Grande: FURG/ABECAN, 2008. p. 27-36.

L'esprit migrateur: essai sur le non-sens commun. Montreal: VLB, 2005.

OUELLETTE-MICHALSKA, Madeleine. Autofiction et dévoilement de soi. Montréal: XYZ, 2007.

PORTO, Maria Bernadette; TORRES, Sonia. Literaturas migrantes. In: FIGUEIREDO, Eurídice (Org.). Conceitos de literatura e cultura. 2. ed. Niterói: EdUFF; Juiz de Fora: Editora UFJF, 2012. p. 225-260.

RICOEUR, Paul. Tempo e narrativa 3. Tradução Roberto Leal Ferreira. Campinas: Papirus, 1997.

Recebido em março de 2014.

Aprovado em junho de 2014. 